order to show the students the impact of using each technique. Budgetary data for your state could be collected for such an exercise.

Our undergraduate research classes develop and administer their own questionnaire. The resulting data are inputted to computer and analyzed by the class. The data are then saved and used as example material and for exercises in other research classes.

Our own research files are also cycled into our teaching. We input all of our data using a spreadsheet. This allows us to input the data into various statistical packages for analysis purposes and into word processing packages for exercise develop- ment. Using our data has two advantages: (1) we already have a large amount of analyzed material making exercise development relatively easy; and (2) by tying the materials to our own research in class discussion we give practical reinforcement to the importance of research in political science.

Overall, the use of the computer should be presented as an enjoyable activity, not a chore. The computer should be treated as a convenient, time-saving tool that is there to assist the students. An instructor with a positive approach will find that teaching with the computer can be fun.

\section{Notes}

1. This article expands on Anne Permaloff's presentation "Using Computers in the Classroom," Innovations in Teaching Political Science Roundtable, Western Political

Science Association Meetings, Seattle, WA, March 1991.

2. SimCity: The City Simulator, MAXIS Software, 1042 Country Club Drive, Suite C, Morgan, CA 94566. Available for IBM,

Tandy, and compatibles. Runs best on a hard disk but will operate on two 5-1/4" 360K floppies.

3. For an examination of these and other relatively inexpensive student statistical packages, see Anne Permaloff and Carl Grafton, “Student Statistical Packages," PS: Political Science \& Politics, XXIII, 1 (December 1989), 820-31.

\title{
Winning Is Not the Only Thing "On the Campaign Trail": An Evaluation of a Micro-Computer Campaign Simulation
}

\author{
Nadine S. Koch, California State University, Los Angeles
}

\begin{abstract}
"On the Campaign Trail: The Ultimate Campaign Computer Simulation" is a microcomputer simulation developed by Fishel and Gopoian for their political campaign management program at Kent State University. The simulation engages the user in a multitude of decision-making activities related to a U.S. Senate campaign by two candidates vying for an open Senate seat in the fictitious state of Tarragon.

Gopoian, Fishel, and Stacey (1987, p. 10) state that the overall teaching goals of the simulation are:
\end{abstract}

1. to provide students with the opportunity to explore the works of Benjamin Page, Stanley Kelley, and Thad Mirer;

2. to provide students with information about U.S. Senate elections between 1970 and 1986 and the key factors that seemed to shape those races;

3. to provide students with insights into high-level campaigns;

4. to sensitize students to the elements and the process of strategic thinking in political campaigns;
5. to facilitate student awareness of the constraints of public opinion on candidate behavior;

6. to allow students to understand the relative importance of money in political campaigns; and

7. to permit students to experience interpersonal cooperation and/or conflict in team decision-making.

This paper will first describe the simulation package, explain how it was used in an upper-level political science course, and lastly, will present evaluations by me and the students of the software and pedagogical value of the microcomputer simuIation. These evaluations will address many of the aforementioned teaching goals.

\section{The Simulation}

The student simulation package consists of three items: one floppy diskette; a 124-page book containing information on U.S. Senate campaigns (incumbency factor, partisanship, political climate of the states, campaign spending, the economy and the vote, etc.), campaign strategies, background information on the state of Tarragon, and instructions on how to play the simulation, including detailed information on the activities listed below; and worksheets to help in planning and implementing the candidate's campaign strategy.

The simulation uses data from the Center for Political Studies 1984 National Election Study. The national voting data have been disaggregated so that each of the 30 counties in Tarragon exhibits a particular demographic and electoral profile. For example, some counties are heavily Republican while others are Democratic strongholds. Some have moderate voting turnouts while others have low or high turnouts. Blacks and Hispanics are represented in some counties and are virtually absent in others. Counties also vary according to the socioeconomic status of their voters. Media viewing habits of the individual voters differ according to their sociodemographic characteristics. In sum, the simulation attempts to replicate the behav- 
ior of the ultimate targets of a Senate campaign: the voters.

Students are assigned to either the Republican candidate, Chip Jones' campaign staff, or to the Democratic candidate, Joe Clark's team. Staffers must make important campaign decisions pertaining to the allocation of resources, finances, and overall campaign strategy. The simulation allows students to make decisions on the following campaign activities:

Travel: Candidates may travel from county to county staging fundraisers or making public appearances.

Media: Staffers may select from nine television stations on which to broadcast their candidate's paid political advertisements. Decisions must be made on the message content of the spot, the time slot for the political spot, and the number of times the spot is to be aired.

Appearances: Candidates are permitted to stage public appearances. If appearances are scheduled, staffers must indicate what issue position their candidate will take in the scheduled public appearance.

Fundraising: Candidates are permitted to visit any of the 30 counties to stage fundraisers. These fundraising events can raise $\$ 25,000-300,000$ depending on the partisanship, size, and socioeconomic characteristics of the selected county. Candidates may receive additional contributions to their campaign depending on their standing in the weekly Gallup Poll. For each percentage point of support over $45 \%$ (excluding undecideds) a candidate will receive $\$ 100,000$ in contributions.

Direct Mail: Candidates may conduct direct mail campaigns. Staffers must decide who will receive the mailings and the message to be communicated. Cost, calculated on the number of targeted voters, is determined before the mailing commences and candidates must have the requisite funds available.

Celebrity Visits: National political figures may be brought to Tarragon to campaign for the candidates.
Survey Research: Candidates may conduct eight different types of polls throughout the course of the campaign.

Both candidates begin their campaigns with rather meager warchests. The Republican candidate, Chip Jones, is allocated $\$ 100,000$ while the Democrat, Joe Clark, begins the race with only $\$ 50,000$ in campaign funds. Televised spot ads, direct mail campaigns, and surveys are activities that require the expenditure of campaign funds. The program requires that the campaign has existing funds to cover the cost of the requested activity, and the cost is immediately deducted from the candidate's coffers. At the end of each week of campaigning the team is notified how much money was contributed to the candidate as a consequence of the week's campaign activities and gains in popular support which result in donations to the candidate. Thirty-eight thousand dollars is deducted from the campaign funds to cover fixed expenses related to campaigning, such as travel, headquarters, staff salaries, etc.

During the first session, users must designate the duration of the campaign which may range from one to ten weeks. The authors recommend a campaign of at least three weeks. Each week's campaign activities may be saved so that the campaign can resume at the next session. The save function also allows for a postelection evaluation of the campaign strategy, identifying tactics that helped to win or alienate voters.

\section{Use of the Simulation in an Upper-Level Political Science Course}

Thirty students were enrolled in the upper-level course "Parties, Campaigns, and Elections."' The class met once a week for a 3-1/2hour class period. The first two hours of class time were devoted to class lectures and discussion. The remaining time was reserved for the computer simulation.

For the purpose of the simulation, the class was divided into six groups, with five students per group. The six groups (randomly designated as three
Democratic and three Republican) paired off, resulting in three separate U.S. Senate campaigns, each with a team representing the Democratic and the Republican candidate. Students used the political science microcomputer laboratory to run their simulations.

A room adjacent to the microcomputer lab was reserved as a caucus/meeting room for the teams who were instructed to appoint or elect team members to fill the following positions: campaign manager, assistant manager, pollster, treasurer, secretary, monitor (spy). An attempt was made to ensure that each group had on its team at least one student who had completed the lower division political science quantitative methods class, and it was recommended that this individual, because of his/her ability to read crosstabulations, be appointed team pollster.

A six-week simulation commenced on the third class meeting. One week prior to the start of the simulation the class was introduced to the microcomputer laboratory and instructed in using the computers. During this session, students were introduced to the simulation software (i.e., getting started, menu options, keyboard mechanics, etc.) and played a one-week practice campaign. Most students had never used a computer before and were quite apprehensive about these activities.

The six-week campaign simulation began during the third week of classes and ended during the eighth week of class. Students were required to write a paper, part of which required an analysis of their team's strategy and what, if any, changes they would make in their team's campaign plan. Completion of the simulation during the eighth week allowed enough time for the analysis of their activities.

Class lectures and assigned readings introduced material pertinent to planning a successful Senate campaign strategy. Topics covered included partisanship and voting behavior, incumbency factor, stages of a campaign, media strategies, information resources, new technologies of campaign politics, and campaign finance. Special attention was focused on the theories of voting behavior upon which this simulation 
is based: Page's "Theory of Ambiguity" and Kelley and Mirer's "Decision Rule." Fishel et al. (1987) explain these theories and their application to the simulation as follows:

Page's theories are relevant to the simulation because they guide the logic of candidate strategies. Candidates must strike a responsive chord with voters' predispositions on issues or concerns. Candidates will appeal to voters with whom they strike such a congruent chord and will turn off voters who disagree with the candidate's appeal. Candidates interested in winning should eschew issues, Page argues, because nearly any issue position a candidate may adopt will of fend a sizable number of voters. A candidate's best strategy under such conditions, Page indicates, is to stress consensual or valence concerns - themes that have nearly universal appeal, such as leadership, experience, and world peace. The simulation provides an ideal experimental setting in which to test such hypotheses about candidate strategy. Among the "issues" that are available to the candidates on most menus are appeals based on leadership, experience, and youth and vigor-each of which is treated as a valence issue by the simulation. (Fishel et al., 69-70)

Kelley and Mirer's theory of candidate preference provides the logic for determining the allocation of points (votes) for the candidates in the simulation:

Kelley and Mirer suggest a very simple model of candidate preference: voters generally vote for the candidate they like the most. Voters add up their net likes and dislikes for all candidates and vote for the one with the highest net approval rating. . . . In summary, Kelley and Mirer's model of how voters choose between candidates provides the basic method by which our simulation aggregates "net approval" of the candidates. (Fishel, et al., p. 70)

Prior to the first week of the simulation, teams were required to complete the first workbook exercise. This entailed the analysis of past electoral data in the state of Tarragon. Students were instructed in how to calculate four important targeting measures: county by county partisan strength, volatility of vote, percent of effort, and voting turnout perfor- mance. The 30 counties in the state of Tarragon were analyzed and then classified on these four variables. On party strength (partisan breakdown of each county), counties were classified as either a base county for the candidate, a competitive county, or as the opposition candidate's base county. On voting volatility (measure of split-ticket voting), counties were classified as most stable for the candidate, modest volatility, or most unstable. For the percent of effort variable (percent of the statewide vote contributed by the county), counties were categorized as being high effort, intermediate effort, or lowest effort. The fourth measure, performance (voting turnout rate for county), also classified the counties as high, intermediate, or low performance.

The completion of this first exercise provided the students with an invaluable data base from which to plan their candidate's campaign strategy. The exercise illustrated the importance of collecting and analyzing past election outcomes and voting behavior in order to identify the "base" vote, essential information in the planning of campaigns. After the completion of this exercise, it was recommended to students that they purchase a benchmark survey during the first week of the campaign. It was explained that the information provided in a benchmark poll would prove useful in strategic planning and as a baseline measure to evaluate subsequent campaign activity.

Outside of the required first worksheet assignment and the recommendation to purchase benchmark polls, students were completely free to purchase any course of action they desired (within the limitations of the simulation). I was present in the computer lab during the simulation and gave advice concerning operation of the hardware, software, and strategy only if it were solicited.

Upon completion of the last week of campaigning, election day is held in the state of Tarragon. The votes are tabulated, and the winner declared. A two-hour period was scheduled for the final week of campaigning and election night activities. After the winners were declared, victory and concession speeches were presented by the teams, and all joined in celebrating the event.

\section{Evaluations}

\section{A. Evaluation of the Simulation as a Class Activity}

Students were asked to complete a short questionnaire asking their opinions about the simulation as a class exercise. They were asked to answer the following five closed-ended questions:

1. How appropriate was the computer simulation as a class exercise?

2. How helpful was the simulation exercise in learning about political campaigning?

3. How do you feel about the time allocated for this project?

4. If this exercise were to be used again, how many weeks of campaigning would you recommend?

5. Should this exercise be required in future "Parties, Campaigns and Elections" classes?

Students were also asked what they liked the most about the simulation class activity and what they least liked about this exercise. Their responses to these open-ended questions will also be reported.

Overall, approximately two-thirds of the students expressed positive reactions to the simulation on every measure. When asked if the simulation should be used in future classes, the response was unanimously affirmative.

Responses fell into three general categories when students described what they liked most about the simulation as a class activity. One, students enjoyed the team aspect of this activity. Interaction with fellow students was a positive experience for most students. Most teams had decided to meet outside of class to develop their team's campaign strategy. The simulation encouraged student interaction, cooperation, and teamwork. Students had commented that the unanticipated consequence of increased collegiality was an additional benefit of the class exercise and that at a commuter institution the opportunities to interact with classmates at this level are virtually nonexistent. A second common response was that the simulation allowed the students to make "real" campaign decisions. The students had 
TABLE 1.

\section{Student Evaluations of the Simulation Exercise}

A. Computer Simulation Appropriate Class Exercise

$\begin{array}{ccccc}\text { very } & \text { somewhat } & \text { somewhat } & \text { very } & \\ \text { appropriate } & \text { appropriate } & \text { inappropriate } & \text { inappropriate } & \\ 87 \%(18) & 13 \%(3) & 0 \% & 0 \% & n=21\end{array}$

B. Simulation Helpful in Learning About Political Campaigning
very
somewhat
helpful
not very
helpful
not at all
helpful
$62 \%(13)$
$38 \%(8)$
$0 \%$
$0 \%$
$\mathrm{n}=21$

Time Allocated for Simulation

too much

too little

$5 \%(1)$

$24 \%(5)$

D. Recommended Duration for Campaign Simulation

$\begin{array}{lccccc}4 \text { weeks } & 6 \text { weeks } & 8 \text { weeks } & 10 \text { weeks } & 12 \text { weeks } & \\ 5 \%(1) & 62 \%(13) & 19 \%(4) & 9 \%(2) & 5 \%(1) & n=21\end{array}$

E. Require Simulation in Future Classes

yes

$100 \%(20)$

no

$0 \%$

$\mathrm{n}=20$

the responsibility of formulating their candidate's campaign strategy and, once implemented, the team was able to get almost immediate feedback on how different strategies influenced the voters. Many students also stated they enjoyed analyzing the historic electoral data from the state of Tarragon and the campaign poll data, which they had the option of purchasing. The simulation taught them the importance of understanding the past electoral performance of the voters and how this information is essential in planning a successful campaign. Students also indicated that the simulation was successful in stressing the importance of survey data in modern campaign politics and that the purchasing of surveys and the analysis of the data became one of the most exciting and challenging aspects of the simulation.

Aside from dissatisfaction with elements of the software which will be discussed in the next section, students indicated two problems with this exercise. First, students commented that a one-week introduction to computers and the simulation software was not sufficient, although they recognized the fact that we were operating under the constraints of a ten-week quarter system. Second, some students felt pressured by the time limits imposed upon team decision-making at the computer. During the course of one week of campaigning, each candidate's team has three turns at the computer. It was decided that each of the three turns would last no more than ten minutes. This rule was imposed so that one week of campaign activity could be completed in little over an hour of class time. Each team's monitor (spy) was responsible for timing their opponent's turn at the com-

\section{The simulation}

encouraged student

interaction, cooperation,

and teamwork. Students

had commented that the

unanticipated consequence

of increased collegiality was an additional benefit of the class exercise. . .

puter terminal. Some students felt pressured, especially if their team had not worked out a strategy during or prior to the class meeting. A number of students acknowledged the pressure and anxiety resulting from the imposed time limits but believed these constraints replicated the less than optimal environment in which "real world" campaigns operate.
Two competing teams had experienced difficulties with this class exercise primarily due to the fact that their teams were comprised of nonpolitical science majors and/or computerphobics. Added to their frustrations were team members and opponents who exhibited unsportsmanlike behavior, creating an environment of distrust and animosity. Each team accused the other of cheating and deceitful maneuvers.

\section{B. Evaluation of the Simulation Software}

Students were asked to evaluate the simulation software and offer recommendations to improve the program. Recommendations fell into two categories: program options and software mechanics. As far as the critique of the simulation as a replication of real world political campaigns, students identified a number of campaign activities that were not, but should have been, program options, and limitations on some existing options that they found to be unrealistic and divorced from the reality of campaign politics.

Students believed the simulation should have included the option for "Get Out the Vote Drives." A number of students indicated they would have enjoyed the challenge of running a Senate campaign against an incumbent rather than a race for an open seat.

In evaluating the existing options, most students decried the inability to broadcast negative campaign spots. The prevalence and effectiveness of negative political spots in modern day political campaigns has not been incorporated into the simulation, and students identified this as a major flaw. Secondly, students argued that the simulation was unrealistic in that it did not allow the candidate to change his position on an issue according to the audience being addressed. Once the candidate takes a stand on an issue the program "locks" in that position and the candidate cannot deviate.

Students recommended three mechanical/technical software improvements. First, some stated a desire for a "Help Screen" option that would explain the various menu options rather than having to con- 
stantly refer to the book. Second, complaints were voiced over the confusing method of identifying the week of the campaign. "Weeks remaining in campaign" would flash on the screen at the end and beginning of each week's session. Students recommended a less confusing indicator such as "Week number ___ of campaign." Lastly, and most important, was the recommendation that safeguards against unintended moves be incorporated into the program. Hitting the "Return" key one too many times would result in the candidate's loss of a turn. Unfortunately, teams who intentionally or unintentionally made this mistake cost themselves or the opposing team a turn. Some also suggested a safeguard double-checking the team's instruction to move the candidate from one county to another ("travel" option). A simple solution to these problems would be the inclusion of a question, in response to these options of "end turn" and "travel," asking the user "Do you want to end turn?" or "Do you want to move candidate to county?"

In addition to these recommendations offered by student users for improving program options and adding technical safeguards, other features of the simulation need to be addressed. As previously discussed, the simulation is based, in part, on Kelley and Mirer's model of candidate preference. The simulation allocates votes based on "net approval" ratings of the respective candidates.

The simulation does not weigh points for intensity of opinion on candidate attributes or issue positions.

Another shortcoming that detracts from the relevance of the simulation to real world campaign politics is related to the communication of the candidates' messages. The simulation does not differentiate between messages communicated to the electorate early in the campaign from those communicated later. In other words, the program does not contain any formula for calculating the effects of primacy versus recency. A formula whereby first appeals are given more weight should be considered by the authors.

Lastly, students and others have commented that the simulation appears to be outdated as far as the choice of campaign themes and issues, voter preferences, and the like. New issues have emerged and gained political saliency. Some of the national political figures used for the simulation celebrity visits may no longer be as popular as they were

\section{The prevalence and} effectiveness of negative political spots in modern day political campaigns has not been incorporated into the simulation, and students identified this

\section{as a major flaw.}

when the simulation data set was first created. Fishel, Gopoian, and Stacey may want to update the simulation by using data from more recent election studies. As the simulation now exists, students are forced to run the Senate campaigns based on the issues, candidate preferences, and partisan distributions of 1984 .

\section{Conclusion}

Students' comments and evaluations of the simulation class exercise suggest that many of the teaching goals as stated by the authors of the program have been achieved. The overwhelming positive response by the students to the campaign simulation also conforms with a number of Greenblat's (Gray and Walcott 1977, p. 296) speculations that classroom simulations might produce an increase in motivation and interests, cognitive learning, enhanced interest/ ability with respect to later coursework, affective learning, and changes in classroom structure and relationships. This evaluation of the campaign simulation did not address formally and scientifically the question of the effect of the simulation on cognitive learning. However, I would speculate that the increased motivation, effort, and interest in the course and coursework would have a positive effect on learning.

Considering the numerous political and logistical problems associated with assigning students to actual political campaigns, I believe this exercise is invaluable for introducing students to the world of modern day campaign politics.

\section{References}

Fishel, M., D. Gopoian, and J. Stacey. 1987. On the Campaign Trail. Washington, DC: Campaigns and Elections.

Gopoian, D., M. Fishel, and J. Stacey. 1987. Taking Your Students on the Campaign Trail. Washington, DC: Campaigns and Elections.

"Simulation, Learning, and Student Attitudes." 1977. In V. Gray and C. Walcott, eds., Teaching Political Science, Vol. 4, No. 3 .

\footnotetext{
About the Author

Nadine S. Koch is an assistant professor of political science at California State University, Los Angeles. Her teaching and research interests include public opinion and polling, political parties, campaigns, and elections, and politics and the media.
} 